\title{
DETERMINATION OF THE $\mathrm{pK}$ VALUES OF THE LUMIFLAVIN TRIPLET STATE BY FLASH PHOTOLYSIS
}

\author{
S. Schreiner, U. Steiner and H. E. A. Kramer* \\ Institut fuer Physikaiische Chemie der Universitaet Stuttgart, Germany
}

(Received 23 May 1974; accepted 19 August 1974)

\begin{abstract}
The triplet-triplet absorption spectra in aqueous solution of the acid $\left({ }^{3} \mathrm{LfH}_{2}{ }^{*}\right)$, the neutral $\left({ }^{3} \mathrm{LfH}\right)$ and the basic ( ${ }^{3} \mathrm{Lf}^{-}$) forms of lumiflavin (6,7,9-trimethylisoalloxazine) were measured by flash photolysis. The $\mathrm{p} K_{a}$ values of the corresponding protolytic equilibria of the lumiflavin triplet were found to be $4 \cdot 4_{3} \pm 0 \cdot 1$ and $9 \cdot 8 \pm 0 \cdot 15$.
\end{abstract}

Quantum yield and product distribution of flavin photoreactions are frequently found to be strongly $\mathrm{pH}$ dependent (Suelter and Metzler, 1960; Penzer, 1970; Carr and Metzler, 1970; Cairns and Metzler, 1971; Haas and Hemmerich, 1972).

In the case of flavin photoreductions the reaction is known to start from the triplet state (Holmstroem and Oster, 1961; Green and Tollin, 1968; Vaish and Tollin, 1970). So for this type of reaction knowledge of the $p K$ values of the flavin triplets will be of great importance for understanding the $\mathrm{pH}$ dependence.

Flavins [in this work lumiflavin (6,7,9-trimethylisoalloxazine)] are amphoteric and, according to Hemmerich (1965), there are three protolytic forms (see also Dudley et al., 1964).

\section{MATERIALS AND METHODS}

Lumiflavin was prepared by photolysis of an alkaline aqueous solution of riboflavin (Knowles and Roe, 1968). As a solvent we used triply distilled water, as buffers $(0.2 M)$ (Schwabe, 1958):

pH 1-3.7 sodium acetate, hydrochloric acid

$\mathrm{pH} 3 \cdot 7-5.6$ sodium acetate, acetic acid pH 6-12 potassium dihydrogen phosphate, sodium hydroxide pH 13 potassium chloride, sodium hydroxide (E. Merck. Darmstadt, Germany).

The high buffer concentration ensures that the protolytic equilibria in the triplet state are really established.

Oxygen was removed by bubbling nitrogen (>99.9\%) through the solutions for $45 \mathrm{~min}$. The results with solutions treated in this way were identical to those with solutions degassed by the 'freezepump-and-thaw' procedure.

The flash apparatus was the same as described earlier (Fischer,<smiles>C=Cc1cc2c(cc1C)N(C)c1[nH]c(=O)[nH]c(=O)c1N2C</smiles>

Consequently one has to assume the existence of at least three different protolytic forms for the excited states, too. Kavanagh and Goodwin (1948) found a marked change of fluorescence of lumiflavin and riboflavin in the regions of $\mathrm{pH} 2-4$ and 9-10.5. The $\mathrm{p} K$ values of the lumiflavin triplet are still unknown. For flavins, there are only a few investigations of the triplet state with respect to variation of the $\mathrm{pH}$ (Shiga and Piette, 1964; Lhoste et al., 1966; Katan et al., 1971).

In this paper we present the results of our investigations on the triplet-triplet absorption spectra of the acid $\left({ }^{3} \mathrm{LfH}_{2}{ }^{+}\right)$, the neutral $\left({ }^{3} \mathrm{LfH}\right)$ and the basic $\left({ }^{3} \mathrm{Lf}^{-}\right)$forms of the lumiflavin triplet as detected by flash photolysis.

${ }^{*}$ Author to whom correspondence should be addressed.
1964; Kramer and Maute, 1972). The flash energy could be varied between $300 \mathrm{~J}$ and $900 \mathrm{~J}$. The half duration of the flash was about $4.6 \mu \mathrm{s}(300 \mathrm{~J})$ and $6 \mu \mathrm{s}(900 \mathrm{~J})$. The cuvette was surrounded by a Kodak-Wratten filter No. $2 \mathrm{~A}$ which absorbs light of wavelength shorter than $400 \mathrm{~nm}$.

Using the flash apparatus described above (kinetic spectrophotometry) the spectra were recorded point-by-point at intervals of $10 \mathrm{~nm}$ (half-width value $2.5 \mathrm{~nm}$ ) in the spectral region from 300 to $780 \mathrm{~nm}$; the spectra were corrected for stray light.

\section{RESULTS}

Dependence of the lumiflavin triplet-triplet absorption spectrum on $\mathrm{pH}$. Figure 1 shows the transient change in absorption when lumiflavin solutions of $\mathrm{pH}=2, \mathrm{pH}=7$, and $\mathrm{pH}=13$ are flashed. From this the triplet-triplet absorption spectra of the acid $(\mathrm{pH}=2)$, neutral $(\mathrm{pH}=7)$, 


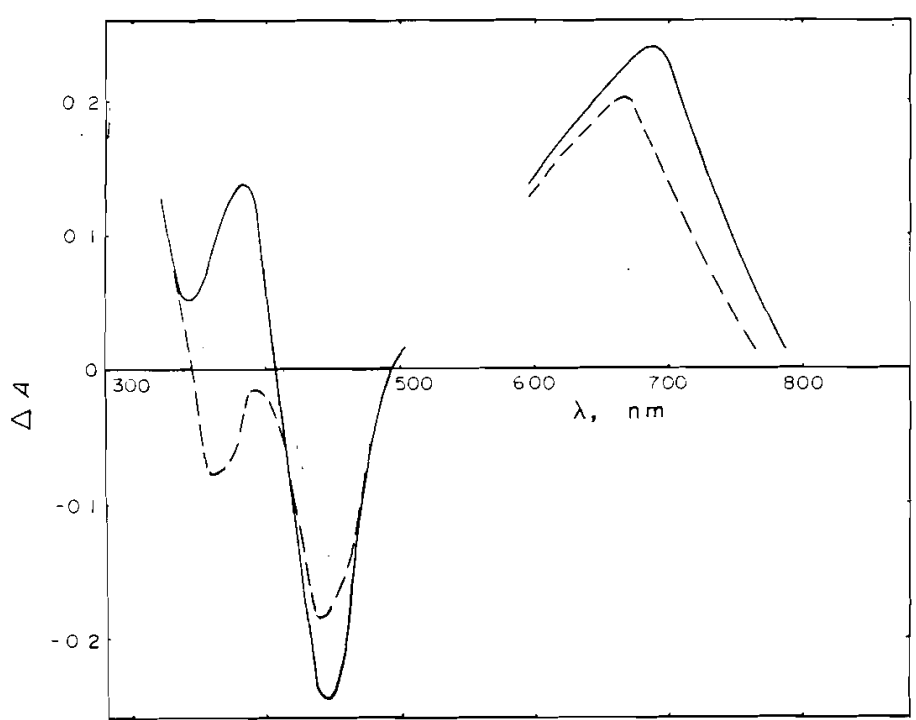

Figure 1. Transient change in absorption observed $8 \mu \mathrm{s}$ after flashing an aqueous solution of lumiflavin; Oxygen-free.

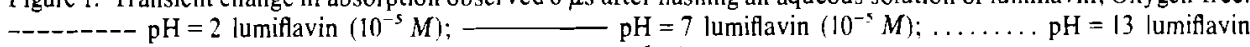
$\left(2 \times 10^{-5} M\right)$

and basic $(\mathrm{pH}=13)$ forms of the lumiflavin triplet were calculated according to the procedure described below (see Fig. 2). The results at pH 7 are in good agreement with those of Knowles and Roe (1968). Correction of the spectra for semiquinone absorption was not necessary, since, using low dye concentrations, almost no semiquinone was formed $8 \mu \mathrm{s}$ after flashing, the moment when all spectra were taken.

Unlike the case of alloxazine, reported by Dekker et al. (1973), in which a considerable amount of long-lived intermediate absorption arises simultaneously with the triplet absorption, there is no long-lived intermediate detectable in our case, when we flash lumiflavin in aerated solutions ( $\mathrm{pH} 2,7,13)$.
In deaerated solutions, only a weak change in optical density is left $300 \mu \mathrm{s}$ after the flash between 500 and $600 \mathrm{~nm}$. due to a long-lived intermediate. No long-lived absorption could be found at the wavelengths where the $\mathrm{p} K$ values were determined.

The absorption of the acid form of the lumiflavin triplet at $370 \mathrm{~nm}$ is smaller than that of the neutral form. A similar observation for 3 -methyllumiflavin was reported by Katan et al. (1971). In the region of longer wavelengths, a small shift of the absorption maximum is found (Fig. 2).

Determination of extinction coefficients. For the calculation of triplet absorption spectra from changes in optical density, there is always the problem that an unknown fraction of ground-state molecules may be present.

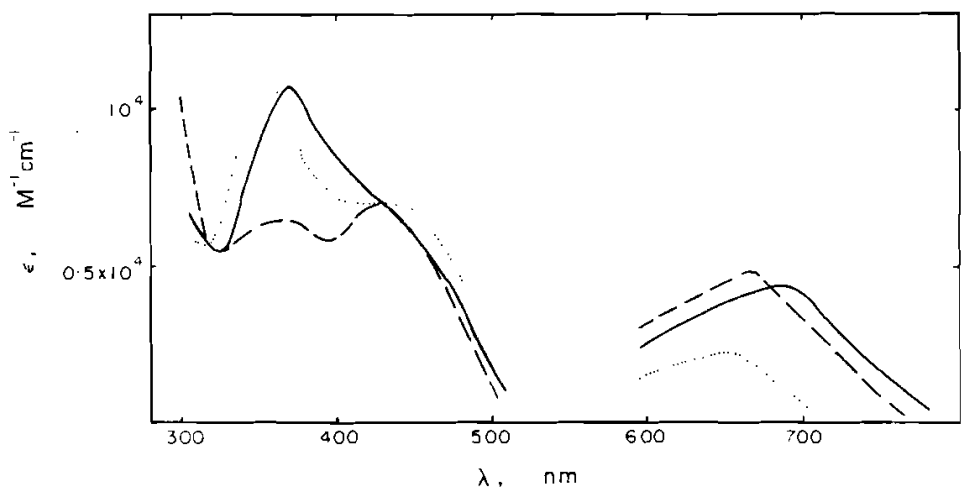

Figure 2. Triplet-triplet absorption spectra (see text) of lumiflavin in aqueous solution $8 \mu \mathrm{s}$ after flashing:---- $\mathrm{pH}=2$ acid triplet form $\left({ }^{3} \mathrm{LfH}_{2}{ }^{+}\right) ;-\mathrm{pH}=7$ neutral triplet form $\left({ }^{3} \mathrm{LfH}\right) ; \ldots . \mathrm{pH}=13$ basic triplet form $\left({ }^{3} \mathrm{Lf}^{-}\right)$; oxygen-free. 
As a matter of fact it should be noted that, without knowledge of the molar extinction coefficients, it is not possible to calculate the ratio of concentrations of two absorbing species from a spectrum of their mixture. This is true even if the extinction coefficient of one species is known.

As can be shown mathematically, one cannot gain final information on the starting concentrations by following the spectral changes due to a change of the ratio of concentrations during time. Hence without an additional assumption one cannot determine the absolute values of the triplet extinction coefficients from the spectra (except for the isosbestic points of ground state-and respective triplet absorption spectrum).

Hadley and Keller (1969) suggested an approximate method for the calculation of triplet spectra, based on the assumption that coincidences of sharp peaks of the ground-state spectrum with those of the triplet spectrum should be very unlikely. Therefore one can assume that, among all possible triplet spectra, the correct one will show the least curvature in the ranges of sharp peaks of the ground-state spectrum.

We can show for all three forms of the lumiflavin triplet that, with increasing flash intensity (flash energy up to $900 \mathrm{~J}$ ), the increase of the optical density, right after the flash, becomes smaller and smaller. From this we conclude that we are close to a triplet population of 100 per cent. The spectra calculated on this assumption (see Fig. 2) are in good agreement with those chosen by means of the Hadley and Keller criteria.

For the extinction coefficients of the long-wavelength maxima we get: acid form $\epsilon_{s}^{67 n}=0.48 \times 10^{4} \mathrm{~cm} \mathrm{M}^{-1}$, neutral form $\epsilon_{n}{ }^{690}=0.44 \times 10^{4} \mathrm{~cm}^{-1} M^{-1}$, basic form $\epsilon_{h}{ }^{650}=0.2 \times 10^{4} \mathrm{~cm}^{-1} M^{-1}$.

Determination of $p \mathrm{~K}$ values. The $\mathrm{p} K_{a}$ value in the acid range can be determined from the decrease of absorbance at $390 \mathrm{~nm}$, since the amount of the triplet produced was constant in the $\mathrm{pH}$ range $3.5 \leq \mathrm{pH} \leq 8$. From Fig. 3a one finds $\mathrm{p} K_{a}=4 \cdot 4_{5} \pm 0 \cdot 1$. In basic solutions $(\mathrm{pH}>9 \cdot 3)$ the amount of the triplet produced decreases with increasing $\mathrm{pH}$. The concentration ratio of basic $\left({ }^{3} \mathrm{Lf}^{-}\right)$to neutral

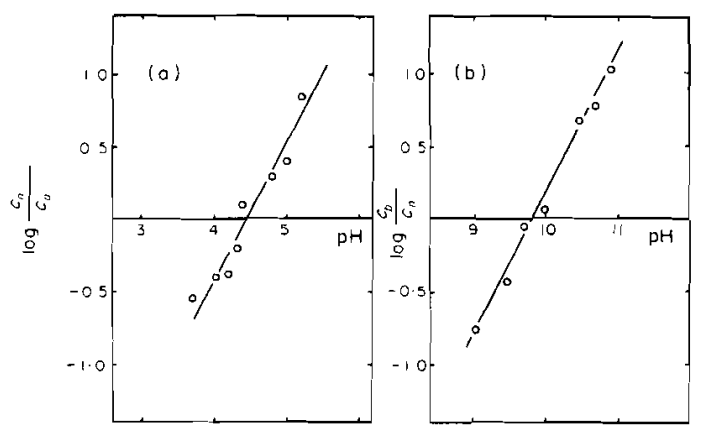

Figure 3. (a) Log plot of the concentration ratio $C_{n} / C_{a}$ of the neutral $\left({ }^{3} \mathrm{LfH}\right)$ to the acid $\left({ }^{3} \mathrm{LfH}_{2}{ }^{+}\right)$lumiflavin triplet form vs $\mathrm{pH}$. (b) Log plot of the concentration ratio $C_{b} / C_{n}$ of the basic ( $\left.{ }^{3} \mathrm{Lf}^{-}\right)$to the neutral $\left({ }^{3} \mathrm{LfH}\right)$ lumiflavin triplet form vs $\mathrm{pH}$. For determination of the concentration ratio, see text.

$\left({ }^{3} \mathrm{LfH}\right)$ triplet $\left(C_{b} / C_{n}\right)$ is obtained from measurements at two different wavelengths $\left(\lambda_{1}=650 \mathrm{~nm} ; \lambda_{2}=700 \mathrm{~nm}\right)$. One gets:

$$
\begin{aligned}
& A^{650}=\epsilon_{b}^{650} \times C_{b} \times d+\epsilon_{n}^{650} \times C_{n} \times d \\
& A^{700}=\epsilon_{b}{ }^{700} \times C_{b} \times d+\epsilon_{n}{ }^{700} \times C_{n} \times d .
\end{aligned}
$$

From Fig. 3b one obtains $\mathrm{p} K_{\mathrm{a}}=9 \cdot 8 \pm 0 \cdot 15$.

Decay of the triplet state. Results of the kinetic measurements at $\mathrm{pH}=2,7$, and 13 demonstrate that the first-order decay constant of the acid triplet form is higher than those of the neutral and basic forms, (Fig. 4, Table 1).

\section{DISCUSSION}

According to calculations of Song (1968) for the neutral isoalloxazine molecule, the nitrogen atom $\mathrm{N}_{3}$ carries the highest electron density, the value being nearly the same in all three states [ground state $\left(S_{0}\right)$, triplet state $\left(T_{1}\right)$, first excited singlet state $\left.\left(S_{1}\right)\right]$. Likewise, nearly the same value is found for the $\mathrm{p} K_{a}$ in the basic range for the three states $\left(S_{n}: \mathrm{p} K_{a} \approx 10\right.$, Dudley et al., 1964; $T_{1}: \mathrm{p} K_{a}=9 \cdot 8 \pm 0 \cdot 15$, this work. Kavanagh and Goodwin (1948) reported changes of fluorescence in the $\mathrm{pH}$ range between 9.0 and

\begin{tabular}{|c|c|c|c|c|c|}
\hline & $\mathrm{pH}$ & $\begin{array}{l}\lambda_{\max } \\
(\mathrm{nm})\end{array}$ & $\begin{array}{c}\epsilon \times 10^{-4} \\
\left(\mathrm{~cm}^{-1} M^{-1}\right)\end{array}$ & $\begin{array}{l}\mathrm{k}^{*}\left(\mathrm{~s}^{-1}\right) \\
\text { apparent first- } \\
\text { order decay } \\
\text { constant }\end{array}$ & $\mathrm{p} K_{\mathrm{a}}$ \\
\hline${ }^{3} \mathrm{LfH}_{2}^{+}$ & 2 & $430 ; 670$ & 0.48 & $3.4_{6} \times 10^{4}$ & $4 \cdot 4_{s} \pm 0 \cdot 1$ \\
\hline${ }^{3} \mathrm{LfH}$ & 7 & $370 ; 690$ & $1.07 ; \quad 0.44 \dagger$ & $1.5, \times 10^{4} \ddagger$ & $9.8 \pm 0.15$ \\
\hline${ }^{3} \mathrm{Lf}^{-}$ & 13 & $350 ; 650$ & $\sim 1 \cdot 1 ; \sim 0.2$ & $1.6 \infty \times 10^{4}$ & \\
\hline
\end{tabular}

Table 1. Characteristics of the different protolytic forms of the lumiflavin triplet state

*Lumiflavin concentration $5 \times 10^{-6} \mathrm{M}$.

$\dagger$ Knowles and Roe (1968): $\epsilon^{\mathrm{ARO}}=0.46 \times 10^{4} \mathrm{~cm}^{-1} \mathrm{M}^{-1}$

$\ddagger$ Knowles and Roe (1968): $k=1 \cdot 11 \times 10^{4} \mathrm{~s}^{-1}$; for an exact analysis of the triplet decay, see Vaish and Tollin (1970). 


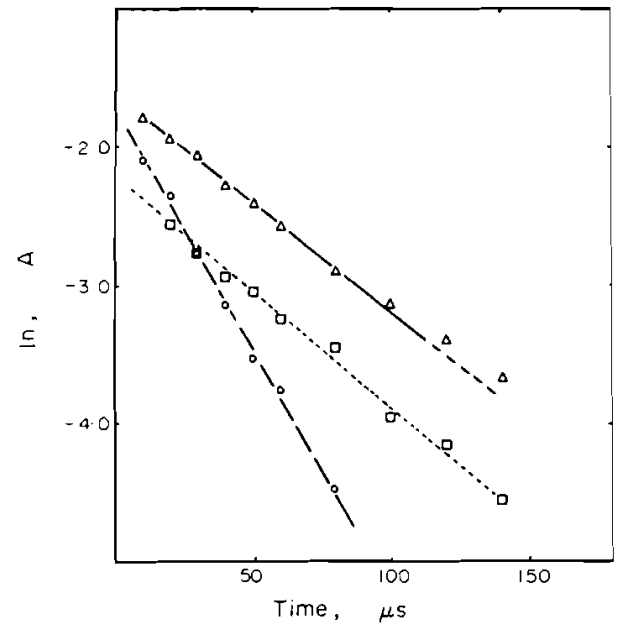

Figure 4. Logarithmic plot of decay of absorbance after flashing $5 \times 10^{-6} \mathrm{M}$ lumifiavin in aqueous solution at different $\mathrm{pH}$ values: $---\mathrm{pH}=2, \lambda_{\text {obs }}=670 \mathrm{~nm} ; \longrightarrow \mathrm{pH}=7, \lambda_{\text {obs }}=690 \mathrm{~nm}$; $\ldots . \mathrm{pH}=13, \lambda_{\mathrm{ons}}=650 \mathrm{~nm}$

10.5 , which leads us to suppose that the $\mathrm{p} K_{a}$ of the $S_{1}$ state lies in this range. Therefore, the simplest explanation would be to attribute this $\mathrm{p} K_{a}$ to protonation at $\mathrm{N}_{3}$. However, our results cannot answer the question of whether or not, in the excited states, protonation at the oxygen atoms could also occur. For the ground state, Dudley et al. (1964) excluded such a possibility.

The $\mathrm{p} K_{a}$ in the acid range corresponds to protonation of the neutral lumiflavin triplet, which might occur at $N_{10}$ or perhaps $\mathrm{O}_{4}$. As J. M. Lhoste has pointed out to us, protonation at $\mathrm{N}_{1}$ is improbable. The phosphorescence of flavin mononucleotide (Lhoste et al., 1966) in strong acids in low-temperature glasses (where the proton may be considered firmly held at $\mathrm{N}_{1}$ ) is blue-shifted relative to the neutral flavin phosphorescence. As follows from the Förster cycle (Förster, 1950; Weller, 1961) the $\mathrm{p} K_{a}$ of the $\mathrm{N}_{\mathrm{I}}$-protonated triplet should therefore be lower than that of the ground state, which is in contradiction to our result. Song (1968) showed that the $N_{1}$ atom carries a higher electronic charge in the ground state than $\mathrm{N}_{10}$ whereas the opposite holds for the first excited singlet state and triplet state.

Acknowledgements-Thanks are due to the Fonds der Chemischen Industrie and to the Deutsche Forschungsgemeinschaft for their financial assistance.

\section{REFERENCES}

Cairns, W. L. and D. E. Metzler (1971) J. Am. Chem. Soc. 93, 2772-2777.

Carr, D. O. and D. E. Metzler (1970) Biochim. Biophvs. Acta 205, 63-71.

Dekker, R. H., B. N. Srinivasan, J. R. Huber, and K. Weiss (1973) Photochem. Photohiol. 18. 457-466

Dudley, K. H., A. Ehrenberg, P. Hemmerich and F. Müller (1964) Helv. Chim. Acta 47, 1354-1383.

Fischer, H. (1964) Z Physik. Chem. NF. 43, 177-190.

Förster, Th. (1950) Z. Elektrochemie 54, 42-46.

Green, M. and G. Tollin (1968) Photochem. Photobiol. 7. 145-153.

Haas, W. and P. Hemmerich (1972) Z. Naturforsch. 27b, 1035-1037.

Hadley, S. G. and R. A. Keller (1969) J. Phys. Chem. 73, 4351-4359.

Hemmerich, P., C. Veeger, and H. C. S. Wood (1965) Angew. Chem. 77, 699-716.

Holmström, B. and G. Oster (1961) J. Am. Chem. Soc. 83, 1867-1871.

Katan, M. B., L. J. Giling and J. D. W. van Voorst (1971) Biochim. Biophys. Acta 234, 242-248.

Kavanagh, F. and R. H. Goodwin (1948) Archiv. Biochem. 20, 315-324.

Knowles, A. and E. M. F. Roe (1968) Photochem. Photobiol. 7, 421-436

Kramer, H. E. A. and A. Maute (1972) Photochem. Photobiol. 15, 7-23.

Lhoste, J. M., A. Haug, and P. Hemmerich (1966) Biochemistry 5, 3290-3300.

Penzer, G. R. (1970) Biochem. J. 116, 733-743.

Schwabe, K. (1958) Fortschritte der pH-Meßtechnik, Verlag Technik Berlin, Anhang 2.

Shiga, T. and L. H. Piette (1964) Photochem. Photobiol 3, 213-222.

Song, P.-S. (1968) Photochem. Photobiol. 7, 3.11-313.

Suelter, C. H. and D. E. Metzler (1960) Biochim. Biophys. Acta 44, 23-33.

Vaish, S. P. And G. Tollin (1970) Bioenergetics 1, 181-192.

Weller. A. (1961) Progress in Reaction Kinetics, Vol. 1, pp. 187-214. Pergamon Press, London. 